\title{
Farmacogenética del cáncer: Estudio de variaciones genéticamente determinadas en la susceptibilidad a cáncer por exposición a xenobióticos
}

\author{
Luis Q uiñones ${ }^{1 a}$, Kuen Lee ${ }^{1}$, Nelson Varela $F^{1 b}$, Mario Escala ${ }^{1}$, \\ Karen G arcía1c, Loreto G odoylc, Andrés Castrolc, \\ Jorge Soto ${ }^{1 d}$, Iván Saavedra2e, Dante Cáceres ${ }^{3 f}$. \\ Cancer pharmacogenetics: \\ Study of genetically determined \\ variations on cancer susceptibility \\ due to xenobiotic exposure
}

Pharmacogenetics is the study of genetically determined variations in the response to drugs and toxic agents, and their implications on disease. Recently, the discipline has acquired great relevancy due to the development of non-invasive molecular techniques that identify genetic variants in human beings. There is also a need to explain the individual differences in susceptibility to drug actions and disease risk. Genetic variants can modify the magnitude of a pharmacologic effect, toxicity threshold, secondary effects and drug interactions. There are approximately thirty families of drug-metabolizing enzymes with genetic variants that cause functional alterations and variations in pharmacologic activity. We summarize the general knowledge about genetic variants of biotransformation enzymes, their relationship with cancer risk and the role of ethnicity. Cancer pharmacogenetics is another promising and exciting research area that will explain why people with an almost identical group of genes, have a different susceptibility to cancer, whose etiology has genetic and environmental components (Rev Méd Chile 2006; 134: 499-515).

(Key w ords: Neoplastic processes; Pharmacogenetics; Toxicogenetics; Xenobiotics)

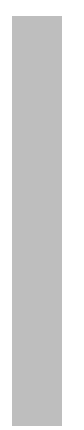
Recibido el 24 de enero, 2005. Acepta Financiamiento: Proyecto FAI-MED-001-06
aBioquímico, $\mathrm{PhD}$
bTecnólogo Médico, MSc
'Estudiante de Medicina
dBioquímico, Químico Farmacéutico
eQuímico Farmacéutico
fMédico Veterinario MPH

Laboratorio de Carcinogénesis Química y Farmacogenética, Programa de Farmacología Molecular y Clínica, ICBM, Facultad de Medicina, Universidad de Chile, Santiago, Chile. 2Laboratorio de Farmacocinética y Biodisponibilidad, Programa de Farmacología Molecular y Clínica, ICBM, Facultad de Medicina, Universidad de Chile. ${ }^{3}$ División de Epidemiología, Escuela de Salud Pública, Facultad de Medicina, Universidad de Chile, Santiago, Chile.

Correspondencia a: Luis Quiñones Sepúlveda. Programa de Farmacología Molecular y Clínica, ICBM, Facultad de Medicina, Universidad de Chile. Apartado Postal 70.000, Santiago 7, Chile. Fono: (562) 6786376. Fax: 7372783. E mail: lquinone@med.uchile.cl 
L a farmacogenética, disciplina que estudia las variaciones genéticamente determinadas en respuesta a agentes externos (xenobióticos), tales como drogas, compuestos tóxicos y contaminantes ambientales, y sus implicancias en la aparición de enfermedades, ha adquirido gran relevancia en la investigación farmacológica ${ }^{1}$. Esto se debe a dos hechos fundamentales: el desarrollo de técnicas no invasivas que permiten identificar con gran eficiencia polimorfismos genéticos en seres humanos y la necesidad de encontrar una explicación a las variaciones en la respuesta a la acción de drogas y al riesgo diferenciado a patologías.

Los estudios farmacogenéticos están dirigidos a identificar genes o productos génicos asociados con enfermedades y, en particular, variantes alélicas en enzimas de biotransformación que alteran la respuesta individual a fármacos. Estas variantes pueden modificar la magnitud del efecto farmacológico, el umbral de toxicidad, la efectividad de la droga, los efectos secundarios e interacciones droga-droga. Es importante entonces, definir perfiles farmacogenéticos de pacientes para determinar posologías adecuadas, evitar reacciones adversas y desarrollar nuevas drogas según el perfil genético-metabólico de los pacientes.

Los estudios farmacogenéticos son útiles en medicina preventiva y clínica, particularmente en el cáncer, enfermedad que necesita de un diagnóstico preciso de factores de riesgo y de información acerca de resistencia y sensibilidad a drogas quimioterapéuticas.

Se conoce, en humanos, cerca de 30 familias de enzimas metabolizadoras de drogas, que presentan polimorfismo (ocurrencia de alelos múltiples en un locus donde al menos dos alelos aparecen con una frecuencia mayor a $1 \%$ en la población general) $)^{2}$. Estos alelos suelen ser responsables de alteraciones funcionales ${ }^{3} \mathrm{y}$, además, proporcionan una base genética para explicar la susceptibilidad individual a ciertas patologías ${ }^{4-8}$. Muchas de estas variaciones fueron identificadas en pacientes o voluntarios que presentaron reacciones adversas a dosis normales de drogas.

En este trabajo se resumen estudios en polimorfismos genéticos de las enzimas de biotransformación CYP1A1, CYP2E1 y GSTs (Tabla 1), su relación con el riesgo de cáncer y su distribución étnica. Restringimos la presente revisión a estas enzimas debido a nuestra experiencia en su estudio y a la magnitud de datos bibliográficos en relación con cáncer, en diferentes poblaciones.

\section{ENZIMAS DE BIOTRANSFORMACIÓN Y SU ASOCIACIÓN CON CÁNCER}

Una gran variedad de enzimas involucradas en el metabolismo de xenobióticos son polimórficas y han sido asociadas a susceptibilidad diferenciada a cáncer ${ }^{9-14}$. En la Tabla 1, se puede apreciar la gran cantidad de variantes alélicas conocidas para las enzimas CYP1A1, CYP2E1 y GSTs y sus efectos en la expresión final de la enzima. Cabe destacar la variante CYP1A1*2A, que no produce cambios en la proteína misma, pero incrementa la velocidad de transcripción al cambiar timina por citosina en la posición 3801 y que ha sido sindicada como una variante asociada a cáncer en chilenos $^{15,16}$.

Las enzimas de biotransformación CYPs de fase I y GSTs de fase II, involucradas en la activación y desintoxicación de muchos carcinógenos potenciales, han sido extensamente estudiadas $9,17,18$. Aunque los resultados obtenidos han sido controvertidos, han demostrado profundas diferencias raciales en las frecuencias alélicas entre asiáticos, caucásicos, africanos e indígenas americanos $^{19-23}$.

El CYP es el sistema metabolizador más importante, responsable de la oxidación de numerosos compuestos endógenos (endobióticos) y exógenos (xenobióticos). Está distribuido en muchos tejidos, siendo más abundante en hígado. Sobre la base de similitudes en secuencias aminoacídicas ${ }^{24}$, se clasifica en familias, subfamilias e isoformas. En humanos, se han identificado 18 familias CYP y 43 subfamilias. De éstas, han sido secuenciados 57 genes y 47 pseudogenes. La nomenclatura de estas enzimas y sus variantes es de amplio consenso y los nuevos acuerdos al respecto se actualizan constantemente (http//drnelson.utmem.edu/CytochromeP450.html).

Diversos estudios sugieren que las diferencias en los niveles basales de CYP constituyen una de las principales fuentes de variabilidad interindividual en la respuesta a xenobióticos ${ }^{25}$. En este contexto, se ha demostrado, mediante numerosos estudios, correlaciones entre diversas actividades del CYP y la generación de cáncer en diversos tejidos $^{26-28}$. Aunque algunos investigadores no 
Tabla 1. Alelos humanos conocidos para las isoenzimas C YP1A1, CYP2E 1 y GSTs

\begin{tabular}{|c|c|c|c|c|}
\hline Alelo & Cambio nucleotídico & Nombre trivial & Efecto en proteína & Referencia \\
\hline CYP1A1*1A & Ninguno & Silvestre & Ninguno & Kawajiri et al, $1986^{34}$ \\
\hline CYP1A1*1B & C-3219T & ND & NA & Smart and Daly, $2000^{128}$ \\
\hline CYP1A1*1C & G-3229A & ND & NA & Smart and Daly, 2000 \\
\hline CYP1A1*2A & T3801C & M1(Msp1) & NA & Hirvonen et al, $1992^{39}$ \\
\hline CYP1A1*2B & A2455G; T3801C & Nco1 y Msp1 & I462V & Hayashi et al, $1991^{129}$ \\
\hline CYP1A1*2C & A2455G & M2 (Ncol) & $\mathrm{I} 462 \mathrm{~V}$ & Zhang et al, $1996^{130}$ \\
\hline CYP1A1*3 & T3205C & M3(AARFLP) & ND & Crofts et al, $1993^{35}$ \\
\hline CYP1A1*4 & C2453A & M4 & T461N & Cascorbi et al, $1996^{37}$ \\
\hline CYP1A1*5 & C2461A & ND & R464S & Chevalier et al, $2001^{131}$ \\
\hline CYP1A1*6 & G1636T & ND & M331I & Chevalier et al, 2001 \\
\hline CYP1A1*7 & Inserción de T entre 2346_2347 & $\mathrm{NA}$ & Cambio de marco de lectura & Saito $S$ et al, $2003^{131}$ \\
\hline CYP1A1*8 & T2414A & ND & I448N & Saito S et al, 2003 \\
\hline CYP1A1*9 & C2461T & ND & $\mathrm{R} 464 \mathrm{C}$ & Saito S et al, 2003 \\
\hline CYP1A1*10 & C2500T & ND & R477W & Saito S et al, 2003 \\
\hline CYP1A1*11 & C2546G & ND & P492R & Saito S et al, 2003 \\
\hline CYP2E1*1A & Ninquno & Silvestre & Ninquno & Umeno et al, $1988^{132}$ \\
\hline CYP2E1*1B & C9896G & Taq1- & $\mathrm{ND}$ & McBride et al, $1987^{133}$ \\
\hline CYP2E1*1C & 6 repeticiones(extremo 5') & ND & NA & Hu et al, 1999134 \\
\hline CYP2E1*1D & 8 repeticiones(extremo $5^{\prime}$ ) & Dra1 y Xba1 & NA & McCarver et al,1998135 \\
\hline CYP2E1*2 & G1132A & ND & $\mathrm{R} 76 \mathrm{H}$ & Hu et al, 1997 \\
\hline CYP2E1*3 & G10023A & ND & V389I & Hu et al, 1997 \\
\hline CYP2E1*4 & G4768A & ND & V179I & Fairbrother et al, $1998^{136}$ \\
\hline CYP2E1*5A & G-1293C, C-1053T, T7632A & Pst1, Rsa1 y Dra1 & NA & Watanabe et al, $1994^{69}$ \\
\hline СYР2Е1*5В & G-1293C, C-1053T & Pst1, Rsal (c2) & NA & Watanabe et al, 1994 \\
\hline СYP2E1*6 & $\mathrm{T} 7632 \mathrm{~A}$ & $\operatorname{Dr} 1(\mathrm{C})$ & NA & Persson et al, $1993^{112}$ \\
\hline CYP2E1*7A & T-333A & ND & NA & Fairbrother et al, 1998 \\
\hline CYP2Е1*7B & G-71T, T-333A & ND & NA & Fairbrother et al, 1998 \\
\hline CYP2E1*7C & T-333A, A -352G & ND & NA & Fairbrother et al, 1998 \\
\hline GSTM1*0 & Deleción completa & GSTM1 -/- (Null) & Ausencia & Seidegard et al, $1988^{83}$ \\
\hline GSTM1*A & ND & ND & Homodímero? & Fryer A et al, $1993^{137}$ \\
\hline GSTM1*B & ND & ND & Heterodímero? & Fryer A et al, 1993 \\
\hline GSTM $3 *$ A & Deleción 3 pb (intrón 6) & GSTM3 & NA & Yengi L et al, $1996^{138}$ \\
\hline GSTM3*B & & GSTM3 -/- & Ausencia & Yengi L et al, 1996 \\
\hline GSTT1*0 & Deleción completa & GSTT1 -/- & Ausencia & Pemble et al, $1994^{90}$ \\
\hline GSTP1*A & Ninguna & Silvestre & Ninguno & Ali-Osman et al, $1997^{139}$ \\
\hline GSTP1*B & A313G (exón5) & ND & $\mathrm{I} 105 \mathrm{~V}$ & To-Figueras J et al, 1999140 \\
\hline \multirow[t]{2}{*}{ GSTP1*C } & A313G (exón5) & ND & I105V & Park J et al, 1999141 \\
\hline & C341T(exón 6) & ND & A114V & \\
\hline \multirow[t]{2}{*}{ GSTA*A1 } & G-1142C & ND & NA & Bredschneider et al, $2002^{80}$ \\
\hline & G-631T & ND & & \\
\hline GSTA*A2 & G-1142C & ND & NA & Bredschneider et al, 2002 \\
\hline GSTA*A3 & G-631T & ND & NA & Bredschneider et al, 2002 \\
\hline \multirow[t]{4}{*}{ GSTA*B1 } & T-567G & ND & NA & Bredschneider et al, 2002 \\
\hline & C-69T & ND & NA & \\
\hline & G-52A & ND & NA & \\
\hline & A375G (exón 5) & ND & Ninguno & \\
\hline \multirow[t]{5}{*}{ GSTA*B2 } & G-1142C & ND & NA & Bredschneider et al, 2002 \\
\hline & T-567G & ND & NA & \\
\hline & C-69T & ND & NA & \\
\hline & G-52A & ND & NA & \\
\hline & A375G (exon 5) & ND & Ninguno & \\
\hline
\end{tabular}

ND : No existen datos reportados al respecto. NA: No aplicable. 
han encontrado correlación entre el genotipo y el fenotipo ${ }^{29,30}$, es posible postular el uso de algunas enzimas $\mathrm{P} 450$ como biomarcadores tumorales, particularmente en combinación con otros potenciales marcadores, tales como enzimas de fase II, antioncogenes, enzimas de reparación y genes de resistencia a drogas.

CYP1A1. El gen CYP1A1 humano, localizado en el cromosoma $15 q_{22-24}$, codifica para una enzima de fase I, involucrada en la activación de precarcinógenos provenientes del humo del tabaco o de procesos de combustión incompleta, como el benzo(a)pireno (BaP). Este compuesto es metabolizado a un diol-epóxido mutagénico y carcinogénico (Figura 1) ) $^{31,32}$ en un proceso de 3 etapas. En la primera, se produce la formación de un epóxido, entre las posiciones 7 y 8 , por acción de CYP1A1, luego, este epóxido es hidrolizado por la enzima epóxido-hidrolasa y, finalmente, una nueva acción de CYP1A1 produce un nuevo epóxido en posición 9-10, el 7,8-diol-9,10 epóxido, metabolito reactivo del BaP. Este último, es capaz de formar aductos al unirse covalentemente al ADN a través de guanina y puede iniciar un proceso tumoral o ser desintoxicado por conjugación con glutatión (GSH) por acción de la enzima de fase
II, glutatión transferasa M1 (GSTM1). La mayor actividad de CYP1A1, así como la ausencia de actividad GSTM1 han sido asociadas con riesgo aumentado de cáncer pulmonar ${ }^{33}$.

El gen CYP1A1 completo ha sido secuencia$\mathrm{do}^{34}$ y se ha informado de la existencia de varios alelos. De éstos, cuatro son los más estudiados: CYP1A1*2A, CYP1A1*2C, CYP1A1*3, específico de las poblaciones de origen africano ${ }^{35,36 ;}$ y CYP1A $1 * 4$, encontrado en poblaciones alemanas, polacas y turcas 37,38 .

Según Hayashi et al (1991), CYP1A1*2A se encuentra estrechamente ligado con CYP1A1*2C en asiáticos, mientras que esta relación es débil en caucásicos, como se observó en una población de Finlandia ${ }^{39}$. En nuestros estudios, encontramos una relación en subgrupos de la población chilena, mostrando que la etnia juega un papel importante no sólo en la frecuencia de los alelos, sino también en la interacción entre ellos (datos no publicados). Este argumento es apoyado por estudios de Garte et al (1996), que muestran grandes diferencias interétnicas ${ }^{21}$, particularmente entre grupos africanos nativos ${ }^{36}$. Se observó similares resultados para subpoblaciones indias ${ }^{40}$ y grupos nativos de Brasil y Paraguay ${ }^{41}$. En contraste, se han informado diferencias no significativas

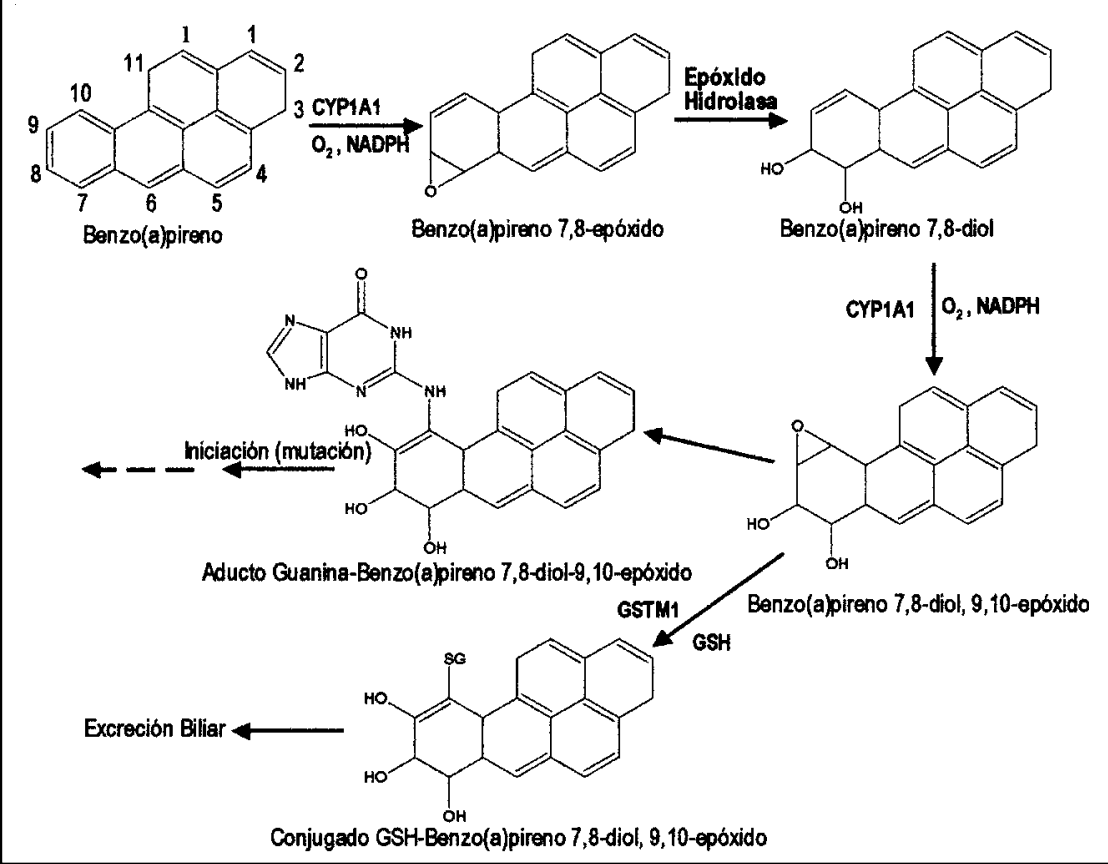

Figura 1. Papel de CYP1A1 y GSTM1 en la bioactivación de benzo(a)pireno. 
entre poblaciones de Tanzania, Sudáfrica, Venda y Zimbawe para los alelos de CYP1A1, GSTM1, GSTP1 y GSTT1 ${ }^{42}$.

Un hallazgo interesante derivó de nuestros estudios, al observar una correlación entre el porcentaje de mezcla aborigen (araucanos o mapuches») y españoles, y la frecuencia del alelo M1 (Msp1) del gen CYP1A1. Analizamos la frecuencia en diferentes subpoblaciones chilenas, incluyendo una población nativa pura y otra caucásica, como mezclas control. Se evaluó el porcentaje de mezcla a través del sistema $\mathrm{ABO}$ y del estrato socioeconómico, según la metodología de Valenzuela (1988) ${ }^{43}$. La Tabla 2 muestra un resumen de

Tabla 2. Porcentaje de mezcla aborigen y frecuencia del alelo M 1 de CYP1A1

\begin{tabular}{|ccl|}
\hline $\begin{array}{c}\text { \% mezcla } \\
\text { aborigen }\end{array}$ & $\begin{array}{c}\text { Frecuencia } \\
\text { alelo M1 }\end{array}$ & Referencia \\
\hline 0 & 0,08 & Quiñones et al (1999) \\
22 & 0,23 & Quiñones et al (1999) \\
24 & 0,30 & Muñoz et al (1998) \\
32 & 0,26 & Acevedo et al (2003) \\
39 & 0,36 & Muñoz et al (1998) \\
97 & 0,83 & Muñoz et al (1998) \\
\hline
\end{tabular}

r: 0,927 los diferentes estudios realizados en Chile y la correlación obtenida entre la frecuencia del alelo mutado y el porcentaje de mezcla aborigen. Interesantemente, la frecuencia para este alelo en mapuches $(0,83)$ es la más alta informada en el mundo $^{22}$. La asociación observada tiene un coeficiente de correlación de 0,927 ( $p<0,0001$ ), lo que permite sugerir al alelo M1 como un posible marcador étnico.

Considerando el papel del CYP1A1 como activador carcinogénico, el efecto propuesto para el alelo M1 en su expresión ${ }^{44}$ y el consumo de tabaco en estas poblaciones ${ }^{45}$, se podría pensar en una alta incidencia de cáncer en los mapuches. Sin embargo, estos factores resultan insuficientes para determinar la incidencia, ya que no se tiene un panorama completo del equilibrio básico intoxicación/desintoxicación de compuestos carcinogénicos en esta población nativa, debido a la ausencia de estudios en otras enzimas de biotransformación. Así por ejemplo, no hay estudios en GSTM1, principal enzima desintoxicadora después de la activación de HAPs por CYP1A1.

CYP2E1. CYP2E1 es una enzima propuesta como posible marcador de cáncer debido a su actividad sobre varios xenobióticos carcinogénicos (benceno, estireno, anilina, etc. ${ }^{46-51}$. La Figura 2 esque-

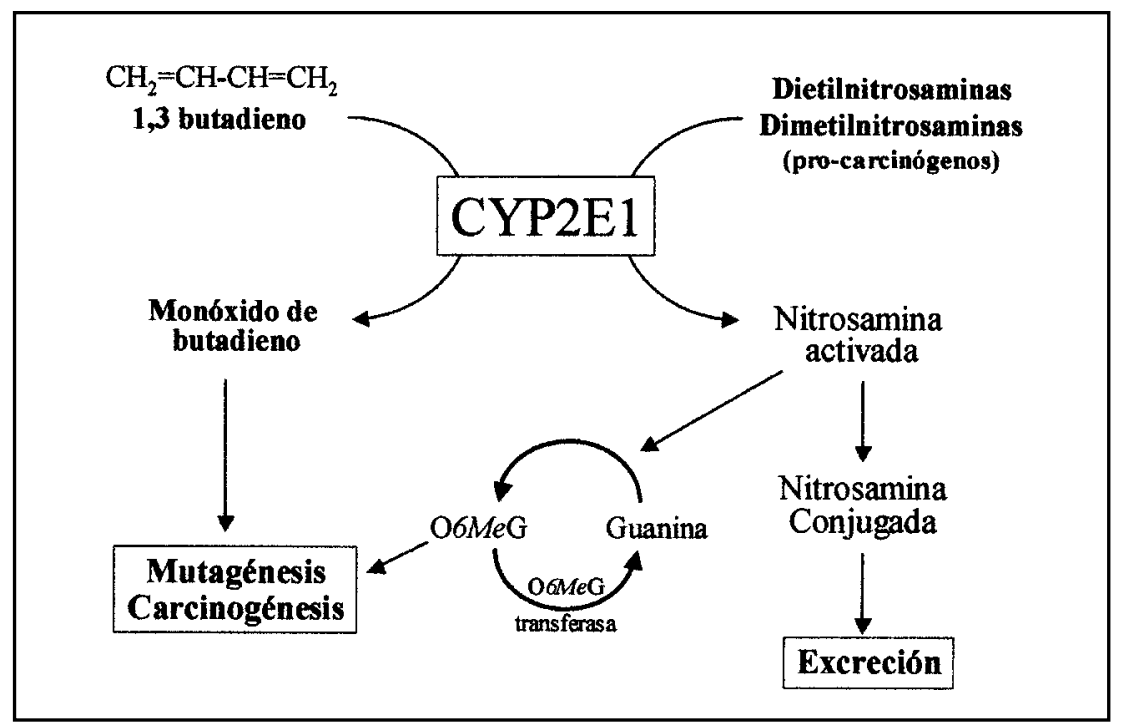

Figura 2. Participación de CYP2E1 en el metabolismo de compuestos carcinogénicos. 
matiza, como a través de su actividad metabólica, CYP2E1 participa en procesos carcinogénicos. Al respecto, es interesante observar su amplio espectro de acción (diferencia fundamental con CYP1A1), debido principalmente a su capacidad de metabolizar compuestos como el 1,3-butadieno, alqueno de bajo peso molecular derivado del petróleo utilizado en la fabricación de caucho y plásticos, y nitrosaminas alquiladas derivadas de la combustión del tabaco. El 1,3-butadieno, por acción de CYP2E1, es transformado en monóxido de butadieno, derivado carcinogénico capaz de unirse a ADN e iniciar un proceso tumoral ${ }^{52}$ y que ha sido asociado con el aumento en la incidencia de variados tipos de cáncer ${ }^{53-55}$. Por su parte, las nitrosaminas alquiladas pueden ser activadas por CYP2E1 para formar O6-metil guanina, conocida estructura precarcinogénica, cuya acción puede revertirse por la enzima 06-me-G transferasa.

La enzima también tiene actividad sobre etanol, acetona, acetol, dietiléter, p-nitrofenol y clorzoxazona $^{56-60}$. La actividad del CYP2E1 es inhibida por compuestos como isotiocianatos, disulfiram y clormetilazol ${ }^{61-63}$ y se induce por etanol e isoniazida ${ }^{64}$. Su actividad se modula también por condiciones como obesidad, ayuno, diabetes y disfunción hepática ${ }^{65,66}$.

La regulación de la expresión del CYP2E1 es compleja, involucra eventos transcripcionales, postrancripcionales y postraduccionales, sobre los cuales juegan un papel importante los polimorfismos ${ }^{67}$ y factores medioambientales, afectando la variación interindividual o poblacional. En el gen CYP2E1 se han descrito tres mutaciones puntuales, RsaI y PstI que se encuentran ligadas y Dra1 que causarían una sobreexpresión del gen 68,69 .

Glutatión S-transferasas (GSTs). La glutatión Stransferasa humana es una familia de multigenes de enzimas diméricas solubles ${ }^{18}$, que incluyen las tipo alfa $(\alpha)$, mu $(\mu)$, pi $(\pi)^{70}$, zeta $(\zeta)^{71}$, sigma $(\sigma)^{72}$, kappa $(\kappa)^{73}$, omega $(\omega)^{74}$ y theta $(\tau)^{75}$, con amplia distribución subcelular y sobreposición parcial de especificidades ${ }^{76}$. Su principal función es desintoxicar compuestos contaminantes, carcinógenos y mutágenos, por conjugación con glutatión (GSH). También, juegan un papel en la protección de tejidos contra especies reactivas de oxígeno $(\mathrm{ROS})^{77}$ e hidroperóxidos lipídicos durante el estrés oxidativo ${ }^{78}$. Ocasionalmente, su actividad lleva a la producción de metabolitos más tóxicos ${ }^{11}$. Diferentes GSTs tienen distintas especificidades de sustrato, aunque algunos sustratos son metabolizados por varias GSTs ${ }^{70,79}$.

Cinco genes GST humanos polimórficos $(\alpha, \mu, \pi, \tau$, $\zeta)$ son investigados como marcadores de riesgo a cáncer ${ }^{18,80}$. Diferencias individuales en la desintoxicación de compuestos reactivos vía GST son frecuentemente el resultado de la deleción de sus genes.

La familia GSTA $(\alpha)$ incluye GSTA1, GSTA2, GSTA3 y GSTA4. La secuencia del gen GSTA1, principal glutatión S-transferasa hepática humana, se ha estudiado recientemente, encontrándose 5 alelos diferentes $\left({ }^{*} \mathrm{~A} 1,{ }^{*} \mathrm{~A} 2,{ }^{*} \mathrm{~A} 3,{ }^{*} \mathrm{~B} 1,{ }^{*} \mathrm{~B} 2\right)$ que no afectan la actividad o expresión de la GSTA1 ${ }^{80}$.

GSTM1 $(\mu)$ es una isoenzima que desintoxica metabolitos de $\mathrm{HAPs}^{81}$ (Figura 1). Esta enzima tiene una actividad deficiente en aproximadamente $50 \%$ de la población caucásica ${ }^{82}$. Se ha demostrado que la pérdida de esta actividad desintoxicante se debe a la herencia de una deleción homocigota del gen ${ }^{83}$, la cual varía con la etnia ${ }^{84}$. La expresión de estos alelos delecionados parece ser diferencialmente regulada ${ }^{85}$ y tiene consecuencias clínicas que explican el riesgo diferencial a varias patologías, incluyendo cáncer.

En la familia GSTT $(\tau)$ se han identificado dos genes, localizados en el cromosoma 22 (q11.2), GSTT1 y GSTT2 ${ }^{86,87}$. Los principales substratos de GSTT1 son diclorometano, óxido de etileno, 1,3butadieno y etano, contenidos en el humo del cigarrillo ${ }^{88}$. Además, GSTT1, GSTM1 y probablemente GSTA1, están involucradas en el metabolismo de hidroperóxidos lipídicos, evidencia indirecta de su participación en enfermedades asociadas a estrés oxidativo ${ }^{78,89}$. El genotipo GSTT1 nulo (ausencia de actividad) se presenta en aproximadamente $38 \%$ de la población británica ${ }^{90}$.

GSTP1 $(\pi)$ al igual que GSTM1, es muy activa en la desintoxicación de metabolitos de $\operatorname{HAPs}^{91}$. El gen ha sido localizado en el cromosoma 11q13, cerca de algunos proto-oncogenes ${ }^{92}$.

Susceptibilidad étnica a cáncer y polimorfismos metabólicos. Varios polimorfismos metabólicos se encontrarían diferencialmente asociados con un aumento en el riesgo a cáncer ${ }^{13,93}$, incluidos los de pulmón ${ }^{4}$, mama ${ }^{94,95}$, próstata ${ }^{15,96-98}$, estómago $^{55}$ y colon ${ }^{99}$ en diferentes poblaciones. En la Tabla 3 se muestra un resumen de la información 
Tabla 3. Estudios de asociación entre variantes alélicas de enzimas de biotransformación CYP1A1, CYP2E 1 y GSTs con cáncer pulmonar a nivel mundial

\begin{tabular}{|c|c|c|c|c|c|c|}
\hline Población & Alelo & $\begin{array}{c}\text { Frecuencia } \\
\text { alélica } \\
\text { controles } \\
(\%)\end{array}$ & $\begin{array}{l}\text { Frecuencia } \\
\text { alélica } \\
\text { pacientes } \\
(\%)\end{array}$ & $\begin{array}{c}\text { Tamaño de la } \\
\text { muestra } \\
\text { (controles/pacientes) }\end{array}$ & OR $(95 \%$ CI $)$ & Referencias \\
\hline Alemania & CYP1A1*4 & 2,9 & 2,9 & $314 / 157$ & NS & Cascorbi et al, $1996^{37}$ \\
\hline \multirow[t]{6}{*}{ Chile } & GSTM1nulo & 24 & 43 & $174 / 60$ & $2,46(1,25-4,82)$ & Quiñones et al, $2001^{16}$ \\
\hline & CYP1A1*2A & 25 & 44 & $174 / 60$ & $4,10(1,8-9,0)$ & Quiñones et al, 2001 \\
\hline & CYP1A1*2C & 33 & 46 & $174 / 60$ & $2,4(1,1-5,3)$ & Quiñones et al, 2001 \\
\hline & CYP2E1*5B & 16 & 12 & $174 / 60$ & NS & Quiñones et al, 2001 \\
\hline & CYP2E1*6 & 21 & 22 & $174 / 60$ & NS & Quiñones et al, 2001 \\
\hline & GSTT1nulo & 10,9 & 6 & $132 / 103$ & NS & Cáceres et al, $2004^{98}$ \\
\hline \multirow[t]{5}{*}{ China } & CYP1A1*2A & ND & ND & $131 / 91$ & NS & Wang B et al, $2004^{143}$ \\
\hline & CYP1A1*2A & 35,6 & 42,6 & $404 / 217$ & $2,0(1,4-2,8)$ & Song et al, $2001^{144}$ \\
\hline & CYP1A1*2C & 25,6 & 34,2 & $404 / 217$ & $1,9(1,3-2,7)$ & Song et al, 2001 \\
\hline & GSTM1nulo & 51 & 71 & $364 / 207$ & $2,34(1,63-3,35)$ & Sun et al, $1997^{145}$ \\
\hline & GSTM1nulo & 66 & 64 & $122 / 76$ & NS & Persson et al, 1999146 \\
\hline Eslovaquia & GSTM1nulo & 59 & 49,6 & $248 / 117$ & $1.7(1.0-2.7)$ & Salagovic et al, $1998^{147}$ \\
\hline España & GSTM1nulo & 50 & 58 & $312 / 160$ & NS & To-Figueras et al, $1997^{148}$ \\
\hline \multirow{4}{*}{$\begin{array}{l}\text { Estados Unidos } \\
\text { (afroamericanos) }\end{array}$} & GSTM1nulo & 23 & 22 & $132 / 108$ & NS & Kelsey et al, $1997^{149}$ \\
\hline & GSTT1nulo & 22 & 25 & $132 / 108$ & NS & Kelsey et al, 1997 \\
\hline & CYP1A1*2A & 5,8 & 1,8 & 137/109 & NS & Ishibe et al, 1997150 \\
\hline & CYP2E1*6 & 13,2 & 10,9 & $114 / 92$ & NS & Wu et al, 1997 \\
\hline \multirow{5}{*}{$\begin{array}{l}\text { Estados Unidos } \\
\text { (caucásicos) } \\
\text { Estados Unidos } \\
\text { (hispanos) }\end{array}$} & CYP1A1*2A & 16 & 18 & $446 / 416$ & $1,5(1,0-2,3)$ & García-Closas et al, 1997102 \\
\hline & GSTM1nulo & 40 & 55 & $146 / 60$ & $1,8(1,0-3,3)$ & Kelsey et al, 1997 \\
\hline & GSTT1nulo & 12 & 17 & $146 / 60$ & NS & Kelsey et al, 1997 \\
\hline & CYP1A1*2A & 14,4 & 16,5 & $158 / 62$ & NS & Ishibe et al, 1997 \\
\hline & CYP2E1*6 & 29,3 & 13,3 & $92 / 45$ & $14,0(1,9-101,5)$ & Wu et al, $1997^{151}$ \\
\hline \multirow{4}{*}{ Brasil } & GSTM1nulo & 43,8 & 54 & $122 / 121$ & NS & Malats et al, $2000^{152}$ \\
\hline & GSTT1nulo & 26,2 & 36,3 & $122 / 121$ & NS & Malats et al, 2000 \\
\hline & CYP1A1*2B & ND & ND & $108 / 99$ & $2,26(1,14-4,47)$ & Hamada G et al, 1995108 \\
\hline & CYP2E1*5B & ND & ND & $108 / 99$ & NS & Hamada G et al, 1995 \\
\hline \multirow[t]{3}{*}{ Finlandia } & GSTM1nulo & 43,7 & 52,9 & $62 / 73$ & NS & Hirvonen et al, $1993^{153}$ \\
\hline & GSTM1nulo & 46,6 & 48 & $294 / 208$ & NS & Saarikoski et al, $1998^{154}$ \\
\hline & GSTT1nulo & 12,7 & 13,3 & $294 / 208$ & NS & Saarikoski et al, 1998 \\
\hline \multirow[t]{2}{*}{ Francia } & GSTM1nulo & ND & ND & $172 / 150$ & NS & Jourenkova et al, 1997155 \\
\hline & GSTT1nulo & ND & ND & $172 / 150$ & NS & Jourenkova et al, 1997 \\
\hline \multirow[t]{3}{*}{ Grecia } & CYP1A1*2A & 1,69 & 4,1 & 178/122 & NS & Dialyna I et al, $2003^{156}$ \\
\hline & GSTM1nulo & 54 & 52 & $178 / 122$ & NS & Dialyna I et al, 2003 \\
\hline & GSTT1nulo & 11 & 17 & $178 / 122$ & NS & Dialyna I et al, 2003 \\
\hline \multirow[t]{3}{*}{ Inglaterra } & GSTM1nulo & 54,7 & 47,2 & $129 / 108$ & NS & Deakin et al, $1996^{157}$ \\
\hline & GSTM1nulo & 53 & 65 & $384 / 111$ & NS & Harrison et al, 1997158 \\
\hline & GSTT1nulo & 14 & 15,7 & $128 / 106$ & NS & Deakin et al, 1996 \\
\hline \multirow{4}{*}{ Japón } & GSTM1nulo & 45,3 & 60,7 & $201 / 178$ & $1,87(1,2-2,9)$ & Kihara et al, $1994^{159}$ \\
\hline & CYP1A1*2A & 10,6 & 16,9 & $375 / 267$ & $\mathrm{~S}$ & Okada et al, 1994160 \\
\hline & CYP2E1*6 & 4,1 & 9,4 & $612 / 532$ & $2,5(0,9-6,5)$ & Oyama et al, $1997^{161}$ \\
\hline & CYP1A1*2A & 17,8 & $\begin{array}{l}7,5 \\
16,5\end{array}$ & $185 / 97$ & NS & Kihara et al, $1995^{101}$ \\
\hline \multirow{5}{*}{$\begin{array}{l}\text { Portugal } \\
\text { Suecia }\end{array}$} & GSTM1nulo & 52 & 44 & $84 / 98$ & NS & Moreira et al, $1996^{162}$ \\
\hline & GSTM1nulo & 50,3 & 45,6 & $161 / 84$ & NS & Nyberg et al, $1997^{163}$ \\
\hline & GSTM1nulo & 54,7 & 54,8 & $530 / 524$ & NS & Alexandrie AK et al, $2004^{164}$ \\
\hline & GSTT1nulo & 14 & 13 & $530 / 524$ & NS & Alexandrie AK et al, 2004 \\
\hline & CYP1A1*2A & 10,6 & 11,1 & $530 / 524$ & NS & Alexandrie AK et al, 2004 \\
\hline
\end{tabular}

ND: No existen datos reportados; NS: La diferencia observada es no significativa; S: Diferencia significativa, OR: Odds Ratio. 
de la literatura en relación con los polimorfismos de los genes CYP1A1, CYP2E1, GSTs y cáncer pulmonar de acuerdo a la etnia. Los datos informados muestran una gran variabilidad en la frecuencia de estas variantes alélicas, que parece depender del perfil genético de las poblaciones estudiadas. Por otro lado, numerosos estudios no han encontrado asociaciones significativas entre estas variantes y la patología, por lo que resulta indispensable realizar más investigaciones en este aspecto, con mayor número de individuos y mejor caracterización étnica, de modo de establecer la efectiva utilidad de estos potenciales biomarcadores de susceptibilidad a cáncer.

Recientemente, Neber y Roe han revisado algunos aspectos de las diferencias genéticas en toxicidad y cáncer, indicando que el polimorfismo MspI de CYP1A1 puede explicar la predisposición genética a riesgo de cáncer por causas medioambientales sólo en japoneses y no en otras etnias ${ }^{93}$. Discrepamos de esta aseveración, pues hemos demostrado una correlación positiva entre el polimorfismo Msp1 con cáncer pulmonar y prostático en la población chilena ${ }^{4,15}$

Por otra parte, personas que poseen genotipos nulos de GST $\mu$ (GSTM1*0) y GST000 (GSTT1*0) no son capaces de desintoxicar varios metabolitos carcinogénicos, presentando un riesgo incrementado en algunos tipos de cánceres ${ }^{8}$. En el caso de GST000 esto es contradictorio, debido a la capacidad de esta enzima de activar algunas substancias a compuestos tóxicos, incluidos varios solventes ${ }^{100}$.

El alelo M1 de CYP1A1, combinado con GSTM1 nulo, se ha asociado con un mayor riesgo a desarrollar cáncer pulmonar entre japoneses, chilenos y caucásicos ${ }^{4,101,102}$, sin embargo, otros estudios no han encontrado asociación 103-105.

La asociación de polimorfismos en CYP2E1 con cáncer aún no es clara y los resultados son controvertidos. Existen estudios que no muestran asociación en poblaciones de Japón ${ }^{106}$, Estados Unidos $^{107}$, Brasil ${ }^{108}$, Finlandia ${ }^{39}$ y Chile ${ }^{4}$ y otros que han encontrado correlaciones en chinos, suecos y coreanos ${ }^{109-113}$.

\section{DiscUSIÓN}

El Proyecto Genoma Humano ha puesto de manifiesto que los genomas de dos personas distintas coinciden en $99,9 \%$ de sus bases nitrogenadas. En otras palabras, la variación en $0,1 \%$ del genoma es lo que diferencia genéticamente a dos personas. Así, mediante la comparación de los genomas de diferentes individuos, se podrá establecer la predisposición genética a ciertas enfermedades e identificar mutaciones y variantes que puedan explicar las diferencias entre las respuestas individuales ante las enfermedades y los tratamientos ${ }^{114}$.

En la terapia frente a una enfermedad, el médico debe observar atentamente la variabilidad interindividual, la cual va intrínsecamente ligada a las características genéticas del sujeto y está modulada por factores fisiológicos, patológicos y ambientales.

En particular, la susceptibilidad individual a cáncer está dada por la combinación entre las características genéticas y la exposición a carcinógenos químicos ${ }^{93}$. Diferencias genéticas en la regulación, expresión y actividad de las enzimas de fase I y II del metabolismo de xenobióticos, pueden ser factores cruciales para definir esta susceptibilidad, debido a la producción de mayor o menor cantidad de metabolitos ${ }^{115}$.

Las investigaciones hasta ahora realizadas, muestran que genotipos o alelos asociados en un estudio con un proceso tumoral, en otro no lo están. Esta diferencia se podnía explicar, por tres razones: 1) diferencias étnicas, que pueden producir variación en la expresión de enzimas que activan o inactivan carcinógenos medioambientales ${ }^{116}$, 2) falta de asociación debido al análisis de grupos muy pequeños o pruebas estadísticas inadecuadas para analizar bajas frecuencias en poblaciones ${ }^{117-119}$, y 3) ligamiento de polimorfismos, que pueden explicar más acertadamente la susceptibilidad a cáncer ${ }^{97,98}$.

Por otro lado, el problema de definir apropiadamente la etnia dificulta la obtención de resultados consistentes. Por ejemplo, no es claro si noruegos y griegos representan un genotipo caucásico clásico, o en los asiáticos, cuál es el genotipo representativo. Esto también ocurre en aborígenes, debido a que no hay una metodología apropiada para definir genéticamente las poblaciones, dado el alto grado de mezcla interracial. Se observa un modelo similar en africanos, donde hay una alta diversidad genética.

Los resultados de asociación de variantes genéticas en enzimas de biotransformación y cáncer, son contradictorios. Aunque se ha observado que 
varios polimorfismos en enzimas metabólicas influencian la susceptibilidad a cáncer, no está claro, por qué un genotipo se asocia a un cáncer y no a otro. Al respecto, Wielandt y cols (2004), informaron diferencias significativas en la frecuencia de variantes genéticas en el gen resistencia múltiple a drogas (MDR1), lo que estaría explicado por diversidad étnica de la población chilena ${ }^{116}$.

Es indudable que dado el carácter multifactorial del cáncer, el análisis de una o dos variantes genéticas de enzimas asociadas al metabolismo de cancerígenos, no será suficiente como herramienta de evaluación de susceptibilidad. Es por ello que la farmacogenética persigue la búsqueda y evaluación de múltiples factores o biomarcadores que en su conjunto describan en mejor forma el potencial genético-metabólico individual frente a cancerígenos. En este contexto, paralelamente se estudian variantes alélicas de antioncogenes, enzimas de reparación y genes de resistencia a drogas $^{116,120-127}$. Asimismo, otro aspecto de gran interés es el estudio de aquellas enzimas de biotransformación específicamente asociadas al metabolismo de los más de 100 agentes químicos utilizados en quimioterapia. Con estos estudios se busca explicar el porqué de una respuesta exacerbada o disminuida de los pacientes y, al mismo tiempo, dirigir la investigación clínica hacia la búsqueda de protocolos de quimioterapia individualizada. El conocimiento de los patrones de

\section{REFERENCIAS}

1. LARes-AssefF I, TRUJILO-JimÉneZ F. [Pharmacogenetics and its importance in the clinical]. Gac Med Mex 2001; 137: 227-36.

2. MeYer UA. Genotype or phenotype: the definition of a pharmacogenetic polymorphism. Pharmacogenetics 1991; 1: 66-7.

3. MCIEOD HL, Evans WE. Pharmacogenomics: unlocking the human genome for better drug therapy. Annu Rev Pharmacol Toxicol 2001; 41: 101-21.

4. QuiÑones L, LuCAS D, Godoy J, Cáceres D, Berthou F, VAREIA N ET aL. CYP1A1, CYP2E1 and GSTM1 genetic polymorphisms. The effect of single and combined genotypes on lung cancer susceptibility in Chilean people. Cancer Lett 2001; 174: 35-44.

5. Matthias C, Bockmuhl U, Jahnke V, Jones PW, Hayes JD, Audersea J et al. Polymorphism in expresión de enzimas involucradas en el metabolismo y de proteínas de transporte de fármacos anticancerosos, permitirá predecir los efectos de éstos y diseñar esquemas de tratamiento que aumenten la eficiencia, disminuyan los efectos adversos y bajen los costos involucrados.

La farmacogenética tiene importantes implicancias clínicas puesto que un médico debe considerar, cuando prescribe un medicamento, que la capacidad inherente de eliminación de éste, varía entre pacientes. Un paciente con metabolismo rápido requerirá dosis más altas y más frecuentes para alcanzar concentraciones terapéuticas y un paciente con metabolismo lento, requerirá dosis más bajas y menos frecuentes para evitar toxicidad, sobre todo para medicamentos con estrecho margen de seguridad. Esto mismo ocurre frente a un agente carcinogénico y podría explicar el porqué de la aparición de la enfermedad en personas poco expuestas.

Las correlaciones entre variantes genéticas de enzimas de biotransformación, exposición medioambiental, respuesta a quimioterapia y susceptibilidad a cáncer, constituyen un área excitante y prometedora de investigación básico-clínica que permitirá una mejor comprensión de por qué individuos con un grupo de genes casi idénticos pueden ser variables en su respuesta a agentes tóxicos, farmacológicos y en la generación de numerosas patologías, en particular del cáncer.

cytochrome P450 CYP2D6, CYP1A1, CYP2E1 and glutathione S-transferase, GSTM1, GSTM3, GSTT1 and susceptibility to tobacco-related cancers: studies in upper aerodigestive tract cancers. Pharmacogenetics 1998; 8: 91-100.

6. Katoh T, Kaneko S, Boissy R, Watson M, Ikemura $\mathrm{K}, \mathrm{BELL}$ DA. A pilot study testing the association between $\mathrm{N}$-acetyltransferases 1 and 2 and risk of oral squamous cell carcinoma in Japanese people. Carcinogenesis 1998; 19: 1803-7.

7. Kiyohara C, Yamamura KI, NaKanishi Y, TaKayama K, Hara N. Polymorphism in GSTM1, GSTT1, and GSTP1 and Susceptibility to Lung Cancer in a Japanese Population. Asian Pac J Cancer Prev 2000; 1: 293-8.

8. Rownson S, Roddam P, Kane E, Roman E, Cartwright R, Jack A et al. Polymorphic variation within the glutathione S-transferase genes 
and risk of adult acute leukaemia. Carcinogenesis 2000; 21: 43-7.

9. Raunio $\mathrm{H}$, Husgafvel-Pursiainen $\mathrm{K}$, Anttila $\mathrm{S}$, Hietanen E, Hirvonen A, Pelkonen O. Diagnosis of polymorphisms in carcinogen-activating and inactivating enzymes and cancer susceptibility, a review. Gene 1995; 159: 113-21.

10. Nebert DW, Mckinnon RA, Puga A. Human drugmetabolizing enzyme polymorphisms: effects on risk of toxicity and cancer. DNA Cell Biol 1996; 15: 273-80.

11. Hengstler JG, Arand M, Herrero ME, Oesch F. Polymorphisms of N-acetyltransferases, glutathione S-transferases, microsomal epoxide hydrolase and sulfotransferases: influence on cancer susceptibility. Recent Results Cancer Res 1998; 154: 47-85.

12. Clapper ML Genetic polymorphism and cancer risk. Curr Oncol Rep 2000; 2: 251-6.

13. Au WW. Life style factors and acquired susceptibility to environmental disease. Int J Hyg Environ Health 2001; 204: 17-22.

14. VAINIO H. Use of biomarkers- new frontiers in occupational toxicology and epidemiology. Toxicol Lett 1998; 102-103: 581-9.

15. Acevedo C, Opazo Jl, Huidobro C, Cabezas J, ITURRIETA J, QUIÑONES L Positive correlation between single or combined genotypes of CYP1A1 and GSTM1 in relation to prostate cancer in Chilean people. Prostate 2003; 57: 111-7.

16. QuiÑones L, LuCAS D, Godoy J, CÁceres D, BerTHOU F, VareIa N ET AL. CYP1A1, CYP2E1 and GSTM1 genetic polymorphisms. The effect of single and combined genotypes on lung cancer susceptibility in Chilean people. Cancer Lett 2001; 174: 35-44.

17. QuiÑones L, GIL L. Induction of rat hepatic P4501A1 by organic extracts from airborne particulate matter in Santiago, Chile. Xenobiotica 1995; 25: 81-9.

18. Strange Rc, Sptteri MA, Ramachandran S, Fryer AA. Glutathione-S-transferase family of enzymes. Mutat Res 2001; 482: 21-6.

19. Stephens EA, Taylor JA, Kaplan N, Yang CH, Hsieh LL, LUCIER GW ET AL. Ethnic variation in the CYP2E1 gene: polymorphism analysis of 695 African-Americans, European-Americans and Taiwanese. Pharmacogenetics 1994; 4: 185-92.

20. Lucas D, Menez C, Girre C, Berthou F, Bodenez P, JoANNET I ET AL. Cytochrome P450 2E1 genotype and chlorzoxazone metabolism in healthy and alcoholic Caucasian subjects. Pharmacogenetics 1995; 5: 298-304.

21. GaRTE S. The role of ethnicity in cancer susceptibility gene polymorphisms: the example of CYP1A1. Carcinogenesis 1998; 19: 1329-32.

22. Muñoz S, Volrath V, Valejos MP, Miquel JF, Covarrubias C, Raddatz A et al. Genetic polymorphisms of CYP2D6, CYP1A1 and CYP2E1 in the South-Amerindian population of Chile. Pharmacogenetics 1998; 8: 343-51.

23. Quiñones L, Berthou F, Vareia N, Simon B, Gil L, LuCAS D. Ethnic susceptibility to lung cancer: differences in CYP2E1, CYP1A1 and GSTM1 genetic polymorphisms between French Caucasian and Chilean populations. Cancer Lett 1999; 141: 167-71.

24. Orelina M, Guajardo V. [Cytochrome P450 activity and its alteration in different diseases]. Rev Méd Chil 2004; 132: 85-94.

25. LiN JH, Lu AY. Interindividual variability in inhibition and induction of cytochrome P450 enzymes. Annu Rev Pharmacol Toxicol 2001; 41: 535-67.

26. Stiborova M, Frei E, Hodek P, Wiessier M, SchmeISER HH. Human hepatic and renal microsomes, cytochromes P450 1A1/2, NADPH:cytochrome $\mathrm{P} 450$ reductase and prostaglandin $\mathrm{H}$ synthase mediate the formation of aristolochic acid-DNA adducts found in patients with urothelial cancer. Int J Cancer 2005; 113: 189-97.

27. Spink BC, Hussain MM, Katz BH, Eisele L, Spink DC. Transient induction of cytochromes P450 1A1 and 1B1 in MCF-7 human breast cancer cells by indirubin. Biochem Pharmacol 2003; 66: 2313-21.

28. Bachmann KA. The Cytochrome P450 Enzymes of Hepatic Drug Metabolism: How are their Activities Assessed In Vivo, and what is their Clinical Relevance? Am J Ther 1996; 3: 150-71.

29. Wedlund PJ, Kimura S, González FJ, Nebert DW. $1462 \mathrm{~V}$ mutation in the human CYP1A1 gene: lack of correlation with either the Msp I $1.9 \mathrm{~kb}$ (M2) allele or CYP1A1 inducibility in a threegeneration family of east Mediterranean descent. Pharmacogenetics 1994; 4: 21-6.

30. Jacquet M, Lambert V, Baudoux E, MuUer M, KreMERS P, Gieien J. Correlation between P450 CYP1A1 inducibility, MspI genotype and lung cancer incidence. Eur J Cancer 1996; 32A: 1701-6. 
31. Shimada T, Yun CH, Yamazaki H, Gautier JC, Beaune PH, Guengerich FP. Characterization of human lung microsomal cytochrome P-450 1A1 and its role in the oxidation of chemical carcinogens. Mol Pharmacol 1992; 41: 856-64.

32. Hazra A, Grossman HB, Zhu Y, Luo S, Spitz Mr, Wu X. Benzo[a]pyrene diol epoxide-induced 9p21 aberrations associated with genetic predisposition to bladder cancer. Genes Chromosomes Cancer 2004; 41: 330-8.

33. Kouri RE, Mckinney CE, Slomiany DJ, Snodgrass DR, Wray NP, McLemore TL. Positive correlation between high aryl hydrocarbon hydroxylase activity and primary lung cancer as analyzed in cryopreserved lymphocytes. Cancer Res 1982; 42: 5030-7.

34. Kawajiri K, Watanabe J, Gotoh O, Tagashira Y, Sogawa K, Fuji-Kuriyama Y. Structure and drug inducibility of the human cytochrome P-450c gene. Eur J Biochem 1986; 159: 219-25.

35. Crofts F, Cosma GN, Currie D, Taioli E, Toniolo P, GARTE SJ. A novel CYP1A1 gene polymorphism in African-Americans. Carcinogenesis 1993; 14: 1729-31.

36. Garte SJ, Trachman J, Crofts F, Toniolo P, Buxbaum J, BAYO S ET AL. Distribution of composite CYP1A1 genotypes in Africans, African-Americans and Caucasians. Hum Hered 1996; 46: 121-7.

37. Cascorbi I, Brockmoler J, Roots I. A C4887A polymorphism in exon 7 of human CYP1A1: population frequency, mutation linkages, and impact on lung cancer susceptibility. Cancer Res 1996; 56: 4965-9.

38. Aynacioglu AS, Cascorbi I, Mrozikiewicz PM, Roots I. High frequency of CYP1A1 mutations in a Turkish population. Arch Toxicol 1998; 72: 215-8.

39. Hirvonen A, Husgafvel-Pursiainen K, Anttila S, Karjalainen A, Sorsa M, Vainio H. Metabolic cytochrome P450 genotypes and assessment of individual susceptibility to lung cancer. Pharmacogenetics 1992; 2: 259-63.

40. Buch S, Kotekar A, Kawle D, Bhisey R. Polymorphisms at CYP and GST gene loci. Prevalence in the Indian population. Eur J Clin Pharmacol 2001; 57: 553-5.

41. Gaspar PA, Kvitko K, Papadopolis LG, Hutz MH, WEIMER TA. High frequency of CYP1A1*2C allele in Brazilian populations. Hum Biol 2002; 74: 235-42.
42. Dandara C, Sayi J, Masimirembwa CM, Magimba A, KaAya S, De Sommers K et al. Genetic polymorphism of cytochrome P450 1A1 (Cyp1A1) and glutathione transferases (M1, T1 and P1) among Africans. Clin Chem Lab Med 2002; 40: 952-7.

43. Valenzuela CY, Carvajal T, Marinkovic K. [Differences in hematologic variables according to $\mathrm{ABO}$ blood group]. Rev Méd Chil 1988; 116: 981-4.

44. Landi MT, Bertazzi PA, Shields PG, Clark G, LuCIER GW, GarTe SJ ET AL. Association between CYP1A1 genotype, mRNA expression and enzymatic activity in humans. Pharmacogenetics 1994; 4: 242-6.

45. Sapunar J, Bravo P, Schneider H, Jiménez M. [Is Mapuche ethnicity a risk factor for hip fracture in aged?]. Rev Méd Chil 2003; 131: 1135-41.

46. Carmelia SG, Borukhova A, AKerkar SA, Hecht SS. Analysis of human urine for pyridine-Noxide metabolites of 4-(methylnitrosamino)-1(3-pyridyl)-1-butanone, a tobacco-specific lung carcinogen. Cancer Epidemiol Biomarkers Prev 1997; 6: 113-20.

47. Johansson I, Ingelman-Sundberg M. Benzene metabolism by ethanol-, acetone-, and benzeneinducible cytochrome P-450 (IIE1) in rat and rabbit liver microsomes. Cancer Res 1988; 48: 5387-90.

48. Thomas PE, Bandiera S, Maines SL, Ryan DE, Levin W. Regulation of cytochrome P-450j, a highaffinity N-nitrosodimethylamine demethylase, in rat hepatic microsomes. Biochemistry 1987; 26: 2280-9.

49. Guengerich FP, Shimada T. Oxidation of toxic and carcinogenic chemicals by human cytochrome P-450 enzymes. Chem Res Toxicol 1991; 4: 391-407.

50. Yang CS, Tu YY, Koop DR, Coon MJ. Metabolism of nitrosamines by purified rabbit liver cytochrome P-450 isozymes. Cancer Res 1985; 45: 1140-5.

51. Yang CS, Yoo JS, Ishizaki H, Hong JY. Cytochrome P450IIE1: roles in nitrosamine metabolism and mechanisms of regulation. Drug Metab Rev 1990; 22: 147-59.

52. Nieusma JL, Ciaffey DJ, Koop DR, Chen W, Peter RM, NelSON SD ET AL. Oxidation of 1,3-butadiene to (R)- and (S)-butadiene monoxide by purified recombinant cytochrome P450 2E1 from rabbit, rat and human. Toxicol Lett 1998; 95: 123-9. 
53. Jackson TE, LuLy PD, Recio L, Schlosser PM, MEDINSKY MA. Inhibition of cytochrome P450 2E1 decreases, but does not eliminate, genotoxicity mediated by 1,3-butadiene. Toxicol Sci 2000; 55: 266-73.

54. Cai L, Yu SZ, Zhan ZF. Cytochrome P450 2E1 genetic polymorphism and gastric cancer in Changle, Fujian Province. World J Gastroenterol 2001; 7: 792-5.

55. Wu MS, Chen CJ, Lin MT, Wang HP, Shun CT, Sheu JC ET AL. Genetic polymorphisms of cytochrome p450 2E1, glutathione S-transferase M1 and $\mathrm{T} 1$, and susceptibility to gastric cancinoma in Taiwan. Int J Colorectal Dis 2002; 17: 338-43.

56. Koop DR, CASAZZA JP. Identification of ethanolinducible P-450 isozyme $3 \mathrm{a}$ as the acetone and acetol monooxygenase of rabbit microsomes. J Biol Chem 1985; 260: 13607-12.

57. Koop DR, Coon MJ. Ethanol oxidation and toxicity: role of alcohol P-450 oxygenase. Alcohol Clin Exp Res 1986; 10 (6 Suppl): 44S-49S.

58. BRady JF, LeE MJ, Li M, IshizaKi H, Yang CS. Diethyl ether as a substrate for acetone/ethanol-inducible cytochrome $\mathrm{P}-450$ and as an inducer for cytochrome(s) P-450. Mol Pharmacol 1988; 33: 148-54.

59. Guengerich FP, KIM DH, IwASAKI M. Role of human cytochrome P-450 IIE1 in the oxidation of many low molecular weight cancer suspects. Chem Res Toxicol 1991; 4: 168-79.

60. Peter R, Bocker R, Beaune PH, Iwasaki M, GuengerlCH FP, YANG CS. Hydroxylation of chlorzoxazone as a specific probe for human liver cytochrome P450IIE1. Chem Res Toxicol 1990; 3: 566-73.

61. LeCLerco I, Desager JP, Horsmans Y. Inhibition of chlorzoxazone metabolism, a clinical probe for CYP2E1, by a single ingestion of watercress. Clin Pharmacol Ther 1998; 64: 144-9.

62. Kharasch ED, Thummel KE. Identification of cytochrome P450 2E1 as the predominant enzyme catalyzing human liver microsomal defluorination of sevoflurane, isoflurane, and methoxyflurane. Anesthesiology 1993; 79: 795807.

63. Gebhardt Ac, Lucas D, Menez JF, Seitz HK. Chlormethiazole inhibition of cytochrome P450 2E1 as assessed by chlorzoxazone hydroxylation in humans. Hepatology 1997; 26: 957-61.

64. GirRe C, Lucas D, Hispard E, Menez C, Daluy S, MENEZ JF. Assessment of cytochrome P4502E1 induction in alcoholic patients by chlorzoxazone pharmacokinetics. Biochem Pharmacol 1994; 47: 1503-8.

65. O'SHEA D, Davis SN, Kim RB, WiLKinson GR. Effect of fasting and obesity in humans on the 6-hydroxylation of chlorzoxazone: a putative probe of CYP2E1 activity. Clin Pharmacol Ther 1994; 56: 359-67.

66. Dilger K, Metzier J, Bode JC, Klotz U. CYP2E1 activity in patients with alcoholic liver disease. J Hepatol 1997; 27: 1009-14.

67. LEBER CS. Cytochrome P-4502E1: its physiological and pathological role. Physiol Rev 1997; 77: 517-44.

68. Hayashi S, Watanabe J, Kawajiri K. Genetic polymorphisms in the 5'-flanking region change transcriptional regulation of the human cytochrome P450IIE1 gene. J Biochem (Tokyo) 1991; 110: 559-65.

69. Watanabe J, Hayashi S, Kawajiri K. Different regulation and expression of the human CYP2E1 gene due to the RsaI polymorphism in the 5'-flanking region. J Biochem (Tokyo) 1994; 116: 321-6.

70. MANNERVIK B. The isoenzymes of glutathione transferase. Adv Enzymol Relat Areas Mol Biol 1985; 57: 357-417.

71. Board PG, Baker Rt, Chelvanayagam G, Jermin LS. Zeta, a novel class of glutathione transferases in a range of species from plants to humans. Biochem J 1997; 328 (Pt 3): 929-35.

72. Kanaoka Y, Fujimori K, Kikuno R, Sakaguchi $Y$, URADE Y, Hayaishi O. Structure and chromosomal localization of human and mouse genes for hematopoietic prostaglandin D synthase. Conservation of the ancestral genomic structure of sigma-class glutathione S-transferase. Eur J Biochem 2000; 267: 3315-22.

73. Pemble SE, Wardie AF, Taylor JB. Glutathione Stransferase class Kappa: characterization by the cloning of rat mitochondrial GST and identification of a human homologue. Biochem J 1996; 319 (Pt 3): 749-54.

74. Board PG, Coggan M, Chelvanayagam G, Easteal S, JeRMiIn LS, Schulte GK ET al. Identification, characterization, and crystal structure of the Omega class glutathione transferases. J Biol Chem 2000; 275: 24798-806.

75. HUSSEY AJ, HAYES JD. Characterization of a human class-Theta glutathione S-transferase 
with activity towards 1-menaphthyl sulphate. Biochem J 1992; 286 (Pt 3): 929-35.

76. Gsur A, Haidinger G, Hinteregger S, Bernhofer G, Schatzl G, Madersbacher S et al. Polymorphisms of glutathione-S-transferase genes (GSTP1, GSTM1 and GSTT1) and prostatecancer risk. Int J Cancer 2001; 95: 152-5.

77. Hayes JD, Strange RC. Potential contribution of the glutathione S-transferase supergene family to resistance to oxidative stress. Free Radic Res 1995; 22: 193-207.

78. Hurst R, Bao Y, Jemth P, Mannervik B, Wimamson G. Phospholipid hydroperoxide glutathione peroxidase activity of human glutathione transferases. Biochem J 1998; 332 (Pt 1): 97-100.

79. Hayes JD, Strange RC. Glutathione S-transferase polymorphisms and their biological consequences. Pharmacology 2000; 61: 154-66.

80. Bredschneider M, Kiein K, Murdter TE, Marx C, Eichelbaum M, Nussler AK et al. Genetic polymorphisms of glutathione S-transferase A1, the major glutathione S-transferase in human liver: consequences for enzyme expression and busulfan conjugation. Clin Pharmacol Ther 2002; 71: 479-87.

81. Ketterer B, Harris JM, Talaska G, Meyer DJ, Pembie SE, TAYLOR JB ET AL. The human glutathione $S$ transferase supergene family, its polymorphism, and its effects on susceptibility to lung cancer. Environ Health Perspect 1992; 98: 87-94.

82. Harada S, Abei M, Tanaka N, Agarwal DP, Goedde HW. Liver glutathione S-transferase polymorphism in Japanese and its pharmacogenetic importance. Hum Genet 1987; 75: 322-5.

83. Seidegard J, Pero RW. The genetic variation and the expression of human glutathione transferase mu. Klin Wochenschr 1988; 66 Suppl 11: 125-6.

84. Lin D, Meyer DJ, Ketterer B, Lang NP, Kadlubar FF. Effects of human and rat glutathione Stransferases on the covalent DNA binding of the N-acetoxy derivatives of heterocyclic amine carcinogens in vitro: a possible mechanism of organ specificity in their carcinogenesis. Cancer Res 1994; 54: 4920-6.

85. Strange RC, Lear JT, Fryer AA. Polymorphism in glutathione S-transferase loci as a risk factor for common cancers. Arch Toxicol Suppl 1998; 20: 419-28.

86. Coggan M, Whitbread L, Whittington A, Board P. Structure and organization of the human theta-class glutathione S-transferase and Ddopachrome tautomerase gene complex. Biochem J 1998; 334 (Pt 3): 617-23.

87. RebBeck TR, Walker AH, JafFe JM, White DL, Wein AJ, Malkowicz SB. Glutathione S-transferase-mu (GSTM1) and -theta (GSTT1) genotypes in the etiology of prostate cancer. Cancer Epidemiol Biomarkers Prev 1999; 8(4 Pt 1): 283-7.

88. LaNDI S. Mammalian class theta GST and differential susceptibility to carcinogens: a review. Mutat Res 2000; 463: 247-83.

89. Yang Y, Sharma R, Zimniak P, Awasthi YC. Role of alpha class glutathione S-transferases as antioxidant enzymes in rodent tissues. Toxicol Appl Pharmacol 2002; 182: 105-15.

90. Pemble S, Schroeder Kr, Spencer Sr, Meyer DJ, HaLuer E, Bolt Hm et al. Human glutathione Stransferase theta (GSTT1): cDNA cloning and the characterization of a genetic polymorphism. Biochem J 1994; 300 (Pt 1): 271-6.

91. Hu X, Singh SV. Differential catalytic efficiency and enantioselectivity of murine glutathione $S$ transferase isoenzymes in the glutathione conjugation of carcinogenic anti-diol epoxides of chrysene and benzo(g) chrysene. Arch Biochem Biophys 1997; 345: 318-24.

92. SMith CM, WeLLS SA, Gerhard DS. Mapping eight new polymorphisms in 11q13 in the vicinity of multiple endocrine neoplasia type 1: identification of a new distal recombinant. Hum Genet 1995; 96: 377-87.

93. NeBER DW, Roe AL Ethnic and genetic differences in metabolism genes and risk of toxicity and cancer. Sci Total Environ 2001; 274: 93-102.

94. Dialyna IA, Arvanitis DA, Spandidos DA. Genetic polymorphisms and transcriptional pattern analysis of CYP1A1, AhR, GSTM1, GSTP1 and GSTT1 genes in breast cancer. Int J Mol Med 2001; 8: 79-87.

95. Mitrunen K, Jourenkova N, Kataja V, Eskeunen M, Kosma VM, Benhamou S et al Glutathione S transferase M1, M3, P1, and T1 genetic polymorphisms and susceptibility to breast cancer. Cancer Epidemiol Biomarkers Prev 2001; 10: 229-36.

96. Murata $M$, Watanabe $M$, Yamanaka $M$, Kubota $Y$, Ito $\mathrm{H}$, Nagao M et al. Genetic polymorphisms in cytochrome P450 (CYP) 1A1, CYP1A2, CYP2E1, glutathione Stransferase (GST) M1 and GSTT1 and susceptibility to prostate cancer in the Japanese population. Cancer Lett 2001; 165: 171-7. 
97. Cáceres D, iturrieta J, Acevedo C, Huidobro C, Varela N, Escala M et al. [Gene-gene and geneenvironment interactions as modifier factors of prostatic cancer risk: «a case-only» design study]. Rev Méd Chil 2004; 132: 961-70.

98. Cáceres D, Iturrieta J, Acevedo C, Huidobro C, VAREIA N, Quinones L. Relationship among metabolizing genes, smoking and alcohol use as modifier factors on prostate cancer risk: Exploring some gene-gene and gene-environment interactions. European Journal of Epidemiology 2005; 20: 78-88.

99. KISS I, SANDOR J, EMBER I. Allelic polymorphism of GSTM1 and NAT2 genes modifies dietaryinduced DNA damage in colorectal mucosa. Eur J Cancer Prev 2000; 9: 429-32.

100. Sherratt PJ, Pulford DJ, Harrison DJ, Green T, HAYES JD. Evidence that human class Theta glutathione S-transferase T1-1 can catalyse the activation of dichloromethane, a liver and lung carcinogen in the mouse. Comparison of the tissue distribution of GST T1-1 with that of classes Alpha, $\mathrm{Mu}$ and Pi GST in human. Biochem J 1997; 326 (Pt 3): 837-46.

101. Kinara M, Noda K. Risk of smoking for squamous and small cell carcinomas of the lung modulated by combinations of CYP1A1 and GSTM1 gene polymorphisms in a Japanese population. Carcinogenesis 1995; 16: 2331-6.

102. García-Closas M, Kelsey KT, Wiencke JK, Xu X, Wain JC, Christiani DC. A case-control study of cytochrome P450 1A1, glutathione S-transferase M1, cigarette smoking and lung cancer susceptibility (Massachusetts, United States). Cancer Causes Control 1997; 8: 544-53.

103. Aktas D, Hascicek M, Sozen S, Ozen H, Tuncbilek E. CYP1A1 and GSTM1 polymorphic genotypes in patients with prostate cancer in a Turkish population. Cancer Genet Cytogenet 2004; 154: 81-5.

104. Yang XR, Wacholder S, Xu Z, Dean M, Clark V, GoLD B ET AL. CYP1A1 and GSTM1 polymorphisms in relation to lung cancer risk in Chinese women. Cancer Lett 2004; 214: 197204.

105. Cheng YJ, Chien YC, Hildesheim A, Hsu MM, Chen IH, Chuang J et al. No association between genetic polymorphisms of CYP1A1, GSTM1, GSTT1, GSTP1, NAT2, and nasopharyngeal carcinoma in Taiwan. Cancer Epidemiol Biomarkers Prev 2003; 12: 179-80.
106. Watanabe J, Yang JP, Eguchi H, Hayashi S, Imai $K$, NAKACHI K ET AL. An Rsa I polymorphism in the CYP2E1 gene does not affect lung cancer risk in a Japanese population. Jpn J Cancer Res 1995; 86: 245-8.

107. Kato S, Shieids PG, Caporaso NE, Hoover RN, TRump BF, SugimuRa H et al. Cytochrome P450IIE1 genetic polymorphisms, racial variation, and lung cancer risk. Cancer Res 1992; 52: 6712-5.

108. Hamada GS, Sugimura $H$, Suzuki I, Nagura $K$, KIYoKaWa E, IwaSe T ET aL. The heme-binding region polymorphism of cytochrome P450IA1 (CypIA1), rather than the RsaI polymorphism of IIE1 (CypIIE1), is associated with lung cancer in Rio de Janeiro. Cancer Epidemiol Biomarkers Prev 1995; 4: 63-7.

109. Wang J, Deng Y, L L, Kuriki K, Ding J, Pan X et al. Association of GSTM1, CYP1A1 and CYP2E1 genetic polymorphisms with susceptibility to lung adenocarcinoma: a case-control study in Chinese population. Cancer Sci 2003; 94: 448-52.

110. Tan W, Song N, Wang GQ, Lu Q, Tang HJ, KADLUBAR FF ET AL. Impact of genetic polymorphisms in cytochrome P450 2E1 and glutathione S-transferases M1, T1, and P1 on susceptibility to esophageal cancer among high-risk individuals in China. Cancer Epidemiol Biomarkers Prev 2000; 9: 551-6.

111. Park GT, Lee OY, Kwon SJ, Lee CG, Yoon BC, HaHM JS ET AL. Analysis of CYP2E1 polymorphism for the determination of genetic susceptibility to gastric cancer in Koreans. J Gastroenterol Hepatol 2003; 18: 1257-63.

112. Persson I, Johansson I, Bergling H, Dahl ML, Seidegard J, Rylander R et al. Genetic polymorphism of cytochrome P4502E1 in a Swedish population. Relationship to incidence of lung cancer. FEBS Lett 1993; 319: 207-11.

113. El-Zein R, Zwischenberger JB, Wood TG, AbdelRahman SZ, Brekelbaum C, Au WW. Combined genetic polymorphism and risk for development of lung cancer. Mutat Res 1997; 38: 189-200.

114. Furness LM, Henrichwark S, EgerTon M. Expression databases-resources for pharmacogenomic R\&D. Pharmacogenomics 2000; 1: 281-8.

115. Garte S, Gaspari L, Alexandrie AK, Ambrosone C, Autrup H, Autrup JL et al. Metabolic gene polymorphism frequencies in control populations. Cancer Epidemiol Biomarkers Prev 2001; 10: $1239-48$. 
116. Wielandt AM, Volrath V, Chianale J. [Polymorphisms of the multiple drug resistance gene (MDR1) in Mapuche, Mestizo and Maori populations in Chile]. Rev Méd Chil 2004; 132: 10618.

117. Gauderman WJ. Sample size requirements for matched case-control studies of gene-environment interaction. Stat Med 2002; 21: 35-50.

118. GaUderman WJ. Sample size requirements for association studies of gene-gene interaction. Am J Epidemiol 2002; 155: 478-84.

119. Vineis P, Malats N. Strategic issues in the design and interpretation of studies on metabolic polymorphisms and cancer. IARC Sci Publ 1999; (148): 51-61.

120. Irarrázabal CE, Rojas $C$, Aracena R, Márquez C, GIL L. Chilean pilot study on the risk of lung cancer associated with codon 72 polymorphism in the gene of protein p53. Toxicol Lett 2003; 144: 69-76.

121. Huang SP, Wu WJ, Chang WS, Wu MT, Chen YY, Chen YJ ET aL. p53 Codon 72 and p21 Codon 31 Polymorphisms in Prostate Cancer. Cancer Epidemiol Biomarkers Prev 2004; 13: 2217-24.

122. Mechanic LE, Marrogi AJ, Welsh Ja, Bowman ED, Khan MA, EnEwold L ET al. Polymorphisms in XPD and TP53 and mutation in human lung cancer. Carcinogenesis 2005; 26: 597-604.

123. Lung FW, Lee TM, Shu BC, Chang FH. p53 codon 72 polymorphism and susceptibility malignancy of colorectal cancer in Taiwan. J Cancer Res Clin Oncol 2004; 130: 728-32.

124. Duell EJ, Miwikan RC, Pittman GS, Winkel S, Lunn RM, TSE CK et al. Polymorphisms in the DNA repair gene XRCC1 and breast cancer. Cancer Epidemiol Biomarkers Prev 2001; 10: 217-22.

125. Benhamou S, Sarasin A. ERCC2 /XPD Gene Polymorphisms and Lung Cancer: A HuGE Review. Am J Epidemiol 2005; 161: 1-14.

126. Sakiyama T, Kohno T, Mimaki S, Ohta T, YanagitaNI N, Sobue T ET aL. Association of amino acid substitution polymorphisms in DNA repair genes TP53, POL, REV1 and LG4 with lung cancer risk. Int J Cancer 2005; 114: 730-7.

127. Plasschaert St, Groninger E, Boezen M, Kema I, De VRIES Eg, Uges D ET AL. Influence of functional polymorphisms of the MDR1 gene on vincristine pharmacokinetics in childhood acute lymphoblastic leukemia. Clin Pharmacol Ther 2004; 76: 220-9.
128. SMART J, DaLY AK. Variation in induced CYP1A1 levels: relationship to CYP1A1, Ah receptor and GSTM1 polymorphisms. Pharmacogenetics 2000; 10: 11-24.

129. Hayashi SI, Watanabe J, Nakachi K, Kawajiri K. PCR detection of an $A / G$ polymorphism within exon 7 of the CYP1A1 gene. Nucleic Acids Res 1991; 19: 4797.

130. Zhang ZY, Fasco MJ, Huang L, Guengerich FP, KAMINSKY LS. Characterization of purified human recombinant cytochrome P4501A1-Ile462 and -Val462: assessment of a role for the rare allele in carcinogenesis. Cancer Res 1996; 56: 3926-33.

131. Chevaler D, Allorge D, Lo-Guidice JM, Cauffiez C, Lhermitte M, LaftTe JJ et al. Detection of known and two novel (M331I and R464S) missense mutations in the human CYP1A1 gene in a French Caucasian population. Hum Mutat 2001; 17: 355.

132. Umeno M, Song BJ, Kozak C, Gelboin HV, GonZÁLEZ FJ. The rat P450IIE1 gene: complete intron and exon sequence, chromosome mapping, and correlation of developmental expression with specific $5^{\prime}$ cytosine demethylation. J Biol Chem 1988; 263: 4956-62.

133. McBride OW, Umeno M, Geiboin HV, GonZÁlez FJ. A Taq I polymorphism in the human P450IIE1 gene on chromosome 10 (CYP2E). Nucleic Acids Res 1987; 15: 10071.

134. Hu Y, Hakkola J, Oscarson M, Ingelman-Sundberg M. Structural and functional characterization of the 5'-flanking region of the rat and human cytochrome P450 2E1 genes: identification of a polymorphic repeat in the human gene. Biochem Biophys Res Commun 1999; 263: 286-93.

135. McCarver DG, Byun R, Hines RN, Hichme M, WegeneK W. A genetic polymorphism in the regulatory sequences of human CYP2E1: association with increased chlorzoxazone hydroxylation in the presence of obesity and ethanol intake. Toxicol Appl Pharmacol 1998; 152: 276-81.

136. Fairbrother KS, Grove J, De Waziers I, Steimel DT, DAY CP, CRESPI CL ET AL. Detection and characterization of novel polymorphisms in the CYP2E1 gene. Pharmacogenetics 1998; 8: 543-52.

137. Fryer AA, Zhao L, Auddersea J, Pearson WR, StRAnge RC. Use of site-directed mutagenesis of allele-specific PCR primers to identify the 
GSTM1 A, GSTM1 B, GSTM1 A,B and GSTM1 null polymorphisms at the glutathione S-transferase, GSTM1 locus. Biochem J 1993; 295 (Pt 1): 313-5.

138. Yengi L, Inskip A, Gilford J, Audersea J, Bailey L, Smith A et al. Polymorphism at the glutathione S-transferase locus GSTM3: interactions with cytochrome P450 and glutathione S-transferase genotypes as risk factors for multiple cutaneous basal cell carcinoma. Cancer Res 1996; 56: 1974-7.

139. Ali-Osman F, Brunner JM, Kutluk tM, Hess K. Prognostic significance of glutathione S-transferase pi expression and subcellular localization in human gliomas. Clin Cancer Res 1997; 3 (12 Pt 1): 2253-61.

140. To-Figueras J, Gene M, Gómez-Catalán J, Pique E, Borrego N, CarRasco JL et al. Genetic polymorphism of glutathione S-transferase P1 gene and lung cancer risk. Cancer Causes Control 1999; 10: 65-70.

141. Park JY, Schantz SP, Stern JC, Kaur T, Lazarus P. Association between glutathione S-transferase pi genetic polymorphisms and oral cancer risk. Pharmacogenetics 1999; 9: 497-504.

142. Quiñones L, Berthou F, Vareia N, Simon B, Gil L, LuCAS D. Ethnic susceptibility to lung cancer: differences in CYP2E1, CYP1A1 and GSTM1 genetic polymorphisms between French Caucasian and Chilean populations. Cancer Lett 1999; 141: 167-71.

143. Wang BG, Chen SD, Zhou WP, Zeng M, Li ZB, CAI XL ET AL. [A case control study on the impact of CYP450 MSPI and GST-M1 polymorphisms on the risk of lung cancer]. Zhonghua Zhong Liu Za Zhi 2004; 26: 93-7.

144. Song N, TAN W, XING D, LiN D. CYP 1A1 polymorphism and risk of lung cancer in relation to tobacco smoking: a case-control study in China. Carcinogenesis 2001; 22: 11-6.

145. Sun W, Zhang J, Hankinson O. A mutation in the aryl hydrocarbon receptor (AHR) in a cultured mammalian cell line identifies a novel region of AHR that affects DNA binding. J Biol Chem 1997; 272: 31845-54.

146. Persson I, Johansson I, Lou YC, Yue QY, Duan LS, BERTILSSON L ET aL. Genetic polymorphism of xenobiotic metabolizing enzymes among Chinese lung cancer patients. Int J Cancer 1999; 81: 325-9.
147. Salagovic J, Kalina I, Stubna J, Habalova V, HrivnaK M, Valansky L et al. Genetic polymorphism of glutathione S-transferases M1 and T1 as a risk factor in lung and bladder cancers. Neoplasma 1998; 45: 312-7.

148. To-Figueras J, Gene M, Gómez-Catalán J, Galan MC, Fuentes M, Ramon JM et al. Glutathione Stransferase M1 (GSTM1) and T1 (GSTT1) polymorphisms and lung cancer risk among Northwestern Mediterraneans. Carcinogenesis 1997; 18: 1529-33.

149. Kelsey KT, Spitz MR, Zuo ZF, Wiencke JK. Polymorphisms in the glutathione S-transferase class mu and theta genes interact and increase susceptibility to lung cancer in minority populations (Texas, United States). Cancer Causes Control 1997; 8: 554-9.

150. Ishibe N, Wiencke JK, Zuo ZF, McMilan A, Spitz M, KeLSEY KT. Susceptibility to lung cancer in light smokers associated with CYP1A1 polymorphisms in Mexican- and African-Americans. Cancer Epidemiol Biomarkers Prev 1997; 6: 1075-80.

151. Wu $\mathrm{X}$, Shi H, Jiang $\mathrm{H}$, Kemp $B$, Hong WK, Delclos GL ET AL. Associations between cytochrome P4502E1 genotype, mutagen sensitivity, cigarette smoking and susceptibility to lung cancer. Carcinogenesis 1997; 18: 967-73.

152. Malats N, Camus-Radon AM, Nyberg F, Ahrens W, Constantinescu V, Mukeria A ET al. Lung cancer risk in nonsmokers and GSTM1 and GSTT1 genetic polymorphism. Cancer Epidemiol Biomarkers Prev 2000; 9: 827-33.

153. Hirvonen A, Husgafvel-Pursiainen K, Anttila S, Karjalainen A, Vainio $\mathrm{H}$. Polymorphism in CYP1A1 and CYP2D6 genes: possible association with susceptibility to lung cancer. Environ Health Perspect 1993; 101 Suppl 3: 109-12.

154. Saarikoski ST, Voho A, Reinikainen M, Anttila S, Karjalainen A, Malaveile C et al. Combined effect of polymorphic GST genes on individual susceptibility to lung cancer. Int J Cancer 1998; 77: 516-21.

155. Jourenkova N, Reinikanen M, Bouchardy C, Husgafvel-Pursiainen $K$, Dayer P, Benhamou S et al. Effects of glutathione S-transferases GSTM1 and GSTT1 genotypes on lung cancer risk in smokers. Pharmacogenetics 1997; 7: 515-8.

156. Dialyna IA, Miyakis S, Georgatou N, Spandidos DA. Genetic polymorphisms of CYP1A1, 
GSTM1 and GSTT1 genes and lung cancer risk. Oncol Rep 2003; 10: 1829-35.

157. Deakin M, Elder J, Hendrickse C, Peckham D, Baldwin D, Pantin C ET aL. Glutathione Stransferase GSTT1 genotypes and susceptibility to cancer: studies of interactions with GSTM1 in lung, oral, gastric and colorectal cancers. Carcinogenesis 1996; 17: 881-4.

158. Harrison DJ, Cantlay AM, Rae F, Lamb D, Smith CA. Frequency of glutathione S-transferase M1 deletion in smokers with emphysema and lung cancer. Hum Exp Toxicol 1997; 16: 356-60.

159. Kinara M, Noda K. Lung cancer risk of GSTM1 null genotype is dependent on the extent of tobacco smoke exposure. Carcinogenesis 1994; 15: 415-8.

160. Okada T, KaWashima K, Fukushi S, Minakuchi T, Nishimura S. Association between a cytochrome P450 CYPIA1 genotype and incidence of lung cancer. Pharmacogenetics 1994; 4: 333-40.

161. Oyama T, Kawamoto T, Mizoue $T$, Sugio $K$, Kodama Y, Mitsudomi T et al. Cytochrome P450
2E1 polymorphism as a risk factor for lung cancer: in relation to p53 gene mutation. Anticancer Res 1997; 17: 583-7.

162. Moreira A, Martins G, Monteiro MJ, Alves M, Dias J, Da Costa JD ET AL. Glutathione Stransferase mu polymorphism and susceptibility to lung cancer in the Portuguese population. Teratog Carcinog Mutagen 1996; 16: 269-74.

163. Nyberg F, Hou SM, Hemminki K, Lambert $B$, Pershagen G. Glutathione S-transferase mu1 and $\mathrm{N}$-acetyltransferase 2 genetic polymorphisms and exposure to tobacco smoke in nonsmoking and smoking lung cancer patients and population controls. Cancer Epidemiol Biomarkers Prev 1998; 7: 875-83.

164. Alexandrie AK, Nyberg F, Warholm M, Rannug A. Influence of CYP1A1, GSTM1, GSTT1, and NQO1 genotypes and cumulative smoking dose on lung cancer risk in a Swedish population. Cancer Epidemiol Biomarkers Prev 2004; 13: 908-14.

Agradecimientos

Los autores desean agradecer a la Srta. Jeannette Iturrieta $G$, por la recopilación de parte de la información incorporada en este manuscrito. A la Comisión Nacional de Investigación Científica y Tecnológica (CONICYT) por el apoyo a su investigación a través de los proyectos FONDECYT 2950034 y 3020043, al Departamento de Investigación de la Universidad de Chile a través del proyecto DID 1102-002 y a la Corporación Nacional del Cáncer (CONAC) por el apoyo financiero y médico-clínico. 